\title{
Abstract \\ Dengue and fluid leakage: is white cell count, platelet count and liver transaminases significantly different in fluid leakage group throughout hospital stay? \\ Dahanayaka $\mathrm{N}^{1 *}$, Agampodi $\mathrm{S}^{2}$, Kodithuwakku $\mathrm{U}^{3}$, Vithanage $\mathrm{S}^{4}$, Rajapakse $\mathrm{R}^{1}$, Ranathunga $\mathrm{K}^{1}$, Siribaddana $\mathrm{S}^{1}$ \\ ${ }^{1}$ Department of Medicine, Faculty of Medicine \& Allied Sciences, Rajarata University of Sri Lanka \\ ${ }^{2}$ Department of Community Medicine, Faculty of Medicine \& Allied Sciences, Rajarata University of Sri Lanka \\ ${ }^{3}$ Department of Radiology, Teaching Hospital Anuradhapura \\ ${ }^{4}$ University Medical Unit, Teaching Hospital Anuradhapura
}

\begin{abstract}
Introduction

Serial ultrasound scanning is the best method to detect fluid leakage in dengue fever. However, it is not being done routinely due to lack of equipment and expertise. Objective of this study was to compare the trends of white cell count, platelet count and liver transaminases according to fluid leakage.

Methods

A cross sectional study was carried out at the University Medical Unit Teaching Hospital Anuradhapura from January to May 2014. Serial ultrasound scans were performed to determine fluid leakage and full blood count, SGOT and SGPT were measured daily till recovery.

Results

Total of 109 confirmed cases of dengue fever were included in this study. These included positive for both NS1 antigen and dengue IgM antibodies, dengue IgM antibodies alone and NS 1 antigen alone in 44, 48 and 17 patients respectively. Fluid leakage was detected among $14(12.8 \%)$ patients. Significantly higher $(p<.05)$ white cell count (WCC), lower platelet count, higher SGPT and SGOT levels were observed among patients with fluid leakage from day 4 to day 8 . WCC and platelet counts drops early among patients with fluid leakage and the lowest levels were detected on day 4 for WCC and day 7 for platelets, compared to day 5 and 8 among patients without fluid leakage. Interestingly, we did not observe differences in PCV among these two groups.

Conclusions

Significantly higher WCC, SGOT and SGPT and significantly lower platelet count is seen among dengue fever patients with fluid leakage throughout hospital stay. However, PCV which is taken as an indicator of fluid leakage is not significantly higher in the fluid leakage group.
\end{abstract}

Key words: Dengue fever; Fluid leakage; Anuradhapura

Copyright: $\bigcirc 2015$ Dahanayaka $\mathrm{N}$ et al. This is an open access article distributed under the Creative Commons Attribution License, which permits unrestricted use, distribution, and reproduction in any medium, provided the original work is properly cited.

* Correspondence : niroshanajd@yahoo.com

Cite this abstract as: Dahanayaka N, Agampodi S, Kodithuwakku U, Vithanage S, Rajapakse R, Ranathunga K, Siribaddana S. Dengue and fluid leakage: is white cell count, platelet count and liver transaminases significantly different in fluid leakage group throughout hospital stay?. Anuradhapura Medical Journal 2015;9 (2Supp):S10. DOI: http://dx.doi.org/10.4038/amj.v9i2Supp.7559 


\section{Submit your next Manuscript to} Anuradhapura

Submit your manuscript at http://amj.sljol.info/ 